\title{
Women's Reproductive Choices: The Impact of Medicaid Funding Restrictions
}

Deborah Haas-Wilson

Smith College, dhwilson@smith.edu

Follow this and additional works at: https://scholarworks.smith.edu/eco_facpubs

Part of the Economics Commons

\section{Recommended Citation}

Haas-Wilson, Deborah, "Women's Reproductive Choices: The Impact of Medicaid Funding Restrictions" (1997). Economics: Faculty Publications, Smith College, Northampton, MA.

https://scholarworks.smith.edu/eco_facpubs/8 


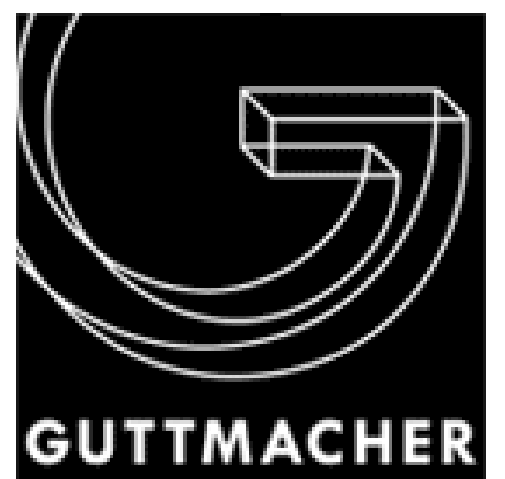

I N S T I T U T E

Women's Reproductive Choices: The Impact of Medicaid Funding Restrictions

Author(s): Deborah Haas-Wilson

Source: Family Planning Perspectives, Vol. 29, No. 5 (Sep. - Oct., 1997), pp. 228-233

Published by: Guttmacher Institute

Stable URL: http://www.jstor.org/stable/2953400

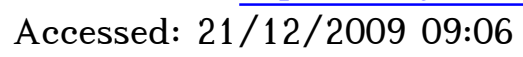

Your use of the JSTOR archive indicates your acceptance of JSTOR's Terms and Conditions of Use, available at http://www.jstor.org/page/info/about/policies/terms.jsp. JSTOR's Terms and Conditions of Use provides, in part, that unless you have obtained prior permission, you may not download an entire issue of a journal or multiple copies of articles, and you may use content in the JSTOR archive only for your personal, non-commercial use.

Please contact the publisher regarding any further use of this work. Publisher contact information may be obtained at http://www.jstor.org/action/showPublisher?publisherCode=agi.

Each copy of any part of a JSTOR transmission must contain the same copyright notice that appears on the screen or printed page of such transmission.

JSTOR is a not-for-profit service that helps scholars, researchers, and students discover, use, and build upon a wide range of content in a trusted digital archive. We use information technology and tools to increase productivity and facilitate new forms of scholarship. For more information about JSTOR, please contact support@jstor.org. 


\section{Women's Reproductive Choices: The Impact of Medicaid Funding Restrictions}

By Deborah Haas-Wilson

\begin{abstract}
As of January 1997, 34 states were enforcing restrictions on Medicaid funding for abortions. Determining whether these restrictions affect women's reproductive decisions was the object of a fixed-effects log-linear analysis using 11 years of data between 1978 and 1992. Results indicate that abortion rates in states with Medicaid funding restrictions are $2 \%$ lower than rates in states with no such restrictions. However, when the supply of abortion providers and the demographic characteristics of the state population are taken into account, the difference is no longer statistically significant. Medicaid funding restrictions have no impact on birthrates, and the result is the same regardless of whether the empirical model takes into account provider availability, demographic characteristics and state sentiment toward women and reproductive rights.
\end{abstract}

(Family Planning Perspectives, 29:228-233, 1997)

$\mathrm{I}$ n 1973, the U.S. Supreme Court ruled in Roe v. Wade that a right of personal 1 privacy exists under the Constitution and that this right includes a woman's decision of whether or not to terminate a pregnancy. However, the Court also ruled that the right of personal privacy is not unqualified and must be considered against state interests in regulation. Since the 1970s, many states have enacted and begun to enforce various abortion restrictions, such as limits on Medicaid funding for abortion services and requirements that unmarried minors notify or obtain the consent of one or both parents or a judge prior to obtaining an abortion. As of January 1997, 34 states were enforcing restrictions on Medicaid funding for abortions, ${ }^{*}$ and 27 states were enforcing parental involvement restrictions. ${ }^{+1}$

Have such restrictions influenced women's reproductive decisions? This article presents an empirical analysis of the relationship between government policies and rates of abortions and births, using data for 11 years during the period 1978-1992.

\section{Previous Research}

Economic theory and some empirical evidence have suggested that both restrictions on Medicaid funding of abortions and parental involvement requirements lower abortion rates among teenagers, ${ }^{2}$ and that Medicaid funding restrictions lower abortion rates among all women of

Deborah Haas-Wilson is associate professor of economics, Smith College, Northampton, Mass. The author thanks Stanley Henshaw, Ted Joyce, Roger Kaufman, Phillip Levine, Robert Ohsfeldt and Mark Wilhelm for helpful comments. reproductive age. ${ }^{3}$ However, other empirical evidence has indicated that state abortion restrictions have no such impact. ${ }^{4}$

The relationship between state-level abortion policies and birthrates is even murkier. Since the birthrate is the product of the pregnancy rate and the ratio of births to pregnancies, state abortion policies may affect birthrates by influencing one or both of these factors. Theory suggests that abortion restrictions may increase the second factor and decrease the first. If levels of sexual activity and contraceptive use remain constant, policies that increase the cost of obtaining an abortion may reduce abortion rates and thus, by increasing the ratio of births to pregnancies, result in higher birthrates.

It has been argued, however, that because increasing the cost of abortion raises the costs of engaging in sexual activity, abortion restrictions may lessen sexual activity and thereby reduce pregnancy rates and birthrates. ${ }^{5}$ This argument assumes that individuals have information on abortion restrictions prior to engaging in sexual activity.

A related view is that the legalization of abortion increased the level of sexual activity among all women (including those who are opposed to abortion). ${ }^{6}$ According to this argument, if women who are willing to obtain abortions increase their level of sexual activity as the costs of abortion decrease, then those who are opposed to abortion will feel more pressure to be sexually active in order to maintain their relationships. In this case, decreasing the costs of abortion may increase the birthrate. However, adherents of this view also argue that increasing the availability of abortion may decrease men's willingness to agree to shotgun marriages in the event of a nonmarital pregnancy, and this may increase women's likelihood of obtaining abortions. In this case, reducing the costs of abortion may reduce birthrates.

Whether state abortion restrictions increase or decrease birthrates is thus an empirical issue, and the existing literature presents mixed results. At least three studies have reported a negative association between public funding of abortions and the birthrate. An analysis of 1982-1988 statelevel data on teenage births found that a higher rate of publicly funded abortions was associated with a lower teenage birthrate. ${ }^{7}$ An examination of birth certificate data for 1975-1990 revealed that Medicaid funding of abortion services reduced the birthrate for white and black women. ${ }^{8} \mathrm{~A}$ study of individual-level North Carolina data for 1980-1993 reported that public funding of abortions was associated with fewer births to women aged $18-29 .{ }^{9}$ Consistent with these findings, an analysis based on state-level data for 1984, 1985 and 1988 found that restrictions on parental involvement were associated with higher adolescent birthrates. ${ }^{10}$

Other research, however, has shown that the estimated impact of abortion restrictions on the birthrate is sensitive to many factors, including the specification of the analytic model and whether the data are examined at the individual level or are grouped by county or state. An analysis of county-level data from the $\mathrm{Na}$ tional Natality Survey found that Medicaid funding restrictions were associated with a lower teenage birthrate for whites and a higher teenage birthrate for non-

*Alabama, Arizona, Arkansas, Colorado, Delaware, Florida, Georgia, Indiana, Iowa, Kansas, Kentucky, Louisiana, Maine, Michigan, Mississippi, Missouri, Nebraska, Nevada, New Hampshire, New Mexico, North Carolina, North Dakota, Ohio, Oklahoma, Pennsylvania, Rhode Island, South Carolina, South Dakota, Tennessee, Texas, Utah, Virginia, Wisconsin and Wyoming.

tAlabama, Arkansas, Delaware, Georgia, Idaho, Indiana, Kansas, Kentucky, Louisiana, Maine, Maryland, Massachusetts, Michigan, Minnesota, Mississippi, Missouri, Nebraska, North Carolina, North Dakota, Ohio, Pennsylvania, Rhode Island, South Carolina, Utah, West Virginia, Wisconsin and Wyoming. 
whites, while parental involvement restrictions were associated with a lower birthrate for white teenagers and had no effect on the birthrate for nonwhites. ${ }^{11}$

A study of state-level birth data for 1977-1988 indicated that Medicaid funding restrictions reduced the birthrate by approximately two births per 1,000 women aged $15-44$, but when state-specific trend variables were added to the model, the effect disappeared..$^{12}$ And an analysis using individual-level data from three southern states and a model that controlled for both time-invariant and time-varying factors within and across states revealed that parental involvement laws were associated with higher birthrates for minors and with surprisingly higher abortion rates for minors. ${ }^{13}$

Other factors that may affect abortion rates and birthrates vary widely across states and over time. For example, in 1992, total public expenditures on contraceptive services (through Title $X$ of the Public Health Service Act, the maternal and child health block grant, Medicaid and the social services block grant) per woman of childbearing age ranged from $\$ 1.40$ in Alaska to $\$ 24.93$ in Oklahoma. Between 1982 and 1992, public spending per woman decreased by almost $40 \%$ in Colorado and Alaska, while it increased by $493 \%$ in Indiana and by $344 \%$ in Oklahoma. ${ }^{14}$

The availability of abortion providers also has shown substantial variation. In 1992, the number of providers per million women aged 15-44 ranged from seven in North Dakota and South Dakota to 117 in Vermont and 196 in Hawaii. Between 1982 and 1992 , the ratio decreased by $60-64 \%$ in North Dakota and Maine, and increased by 14-15\% in Nebraska and Rhode Island. ${ }^{15}$

Empirical evidence points to an association between the availability of family planning services and the reproductive choices of young white women. ${ }^{16}$ Such evidence also suggests that the availability of abortion providers affects women's reproductive choices: Greater availability of providers has been associated with both higher abortion rates ${ }^{17}$ and higher birthrates among teenagers. ${ }^{18}$

\section{The Study}

States have changed their abortion policies at different times; consequently, during any given year, some states enforced abortion restrictions and some did not. Thus, one can think of this empirical analysis of the effects of state abortion policies as a natural experiment design, with a quasi-experimental group and a control group. However, states were not randomly selected into the experimental and control groups; thus, a fixed-effects model is estimated, which removes the influence of any omitted time-invariant, state-level factors that could be correlated with the error term of the empirical model (i.e., the difference between the observed dependent variable and its expected value, given the independent variables) and the abortion policies.

To control for the potential impact of unmeasured state-specific factors that vary over time, the model is also estimated with three proxy variables for state sentiment toward women, nonmarital sex and abortion, and with state-specific trend variables (a time-trend variable interacted with state dummy variables). State-specific trend variables account for linear differences between the states. Further, one can think of this as a pretest-posttest design, since information is available on states prior to their enactment of abortion restrictions.

This study offers at least three major improvements over previous analyses using fixed-effects models and state-level data on abortions and births. First, it includes more recent abortion and birth data.

Second, previous work has assumed that the impact of Medicaid funding restrictions is constant across states and over time. However, if these restrictions affect only the Medicaid-eligible population, one would expect their impact to vary across states and over time, depending on the proportion of the state population that is eligible for the program. Accordingly, since state-level data on abortions and births are not available by income level, this analysis takes a second-best approach and allows the impact of the funding restriction to vary with the size of the Medicaid-eligible population in each state over time.

Third, the inclusion of variables reflecting state sentiment toward women and women's reproductive choices may be important for three interrelated reasons: These sentiments may have a large effect on women's choices; they may have varied in different ways and at different rates in each state over time; and fixed-effects models do not control for state-specific, time-varying factors.

\section{Methodology}

This analysis is based on the assumption that the abortion rate and the birthrate are functions of the determinants of the optimal number of children (such as family income, marital status and employment status), the costs of contraception and the costs of abortion. ${ }^{* 19}$ The variables included in the model are shown with their unweighted means in Table 1.

A key variable is the portion of each year in which states restricted Medicaid funding for abortions. ${ }^{20}$ Between 1978 and 1992, five states and the District of Columbia made long-term changes in their Medicaid funding policies for abortions: Colorado, the District of Columbia, Maryland, Michigan and Pennsylvania started to restrict funding, while Vermont ended abortion funding restrictions. In addition, many states made temporary changes in their Medicaid funding policies for abortions. For example, in 1980, 21 states $^{\dagger}$ funded abortions for rela-

*The abortion rate and birthrate equations are specified as follows:

Rate $_{i t}=a_{o}+a_{1} X_{i t}+a_{2}$ Medicaid restriction ${ }_{i t}$

$+\mathrm{a}_{3}$ Medicaid restriction $\mathrm{x} \%$ in poverty $\mathrm{y}_{\mathrm{it}}$

$+a_{4}$ Abortion providers per 1,000 women $_{\text {it }}$

$+a_{5}$ Public spending on contraception per woman ${ }_{i t}$

$+a_{6}$ Parental involvement not enforced ${ }_{i t}$

$+a_{7}$ Parental involvement enforced

$+a_{8}$ Women as $\%$ of legislators it $_{\text {it }}+$ Year $_{t}+$ State $_{i}$

+ Trend $x$ state $_{i}+u_{i+}$

where $i=1, \ldots 51$ and $t=1978, \ldots 1992 ; X_{i t}$ is a vector of demographic variables (the proportion of the population below the poverty level, women's labor-force participation rate and the marriage rate); year ${ }_{t}$ is a year-specific fixed effect; state $_{i}$ is a state-specific fixed effect; trend $x$ state $_{i}$ is a linear state-specific trend effect; and $\mathrm{u}_{\mathrm{it}}$ is a random error term.

tAlabama, Arkansas, Delaware, Florida, Idaho, Indiana, Iowa, Kansas, Maine, Mississippi, Missouri, Montana, Nebraska, Nevada, New Hampshire, New Mexico, Oklahoma, South Carolina, Texas, Utah and Vermont. 
tively brief periods, but returned to restrictive policies by the end of the year.

As a proxy for the size of the Medicaideligible population, the model uses the proportion of the population living below the poverty line. ${ }^{21}$ To allow the impact of the Medicaid funding restriction to vary with the relative size of the Medicaid-eligible population, the interaction between these two variables is also included.

Two variables are used to assess the impact of government policies that affect the costs of contraceptive services: total public expenditures on contraceptive services per woman of childbearing age $\mathrm{e}^{22}$ and the number of family planning clinics per 1,000 women of childbearing age ${ }^{* 23}$ Increasing either the public subsidy of contraceptive services or the availability of family planning clinics will reduce the price of contraception for some women and thus may affect birthrates and abortion rates. Reducing the price of contraception may increase the probability that a pregnant woman will give birth because with more women using contraceptives, fewer pregnancies will be unintended. ${ }^{24}$

The number of abortion providers per 1,000 women of childbearing age ${ }^{25}$ is included in an attempt to account for differences across states and over time in the time and travel costs of obtaining an abortion. Although one can argue that the availability of abortion providers is endogenous to the model, results of other research justify treating the ratio of providers to women as an exogenous variable: In a two-stage least-squares analysis using the total number of physicians and the total number of hospitals in each state and year as instruments for the number of abortion providers, the two-stage and ordinary least-squares coefficients were not significantly different; ${ }^{26}$ this suggests that the effect of provider availability on the abortion rate within a state is not the result of endogeneity bias.

The fixed-effects model was estimated with time-varying, state-specific proxy variables for state sentiments toward women, nonmarital sex and abortion: the proportion of state legislators who are women, ${ }^{27}$ the portion of the year during which a parental involvement restriction

*Unfortunately, no data are available on the number of persons using contraceptives by state and year. In 1990, $59 \%$ of U.S. women of childbearing age used contraceptives. (See: L. S. Peterson, "Contraceptive Use in the United States: 1982-90," Advance Data from Vital and Health Statistics, No. 260, 1995.)

†Arkansas, California, Connecticut, Hawaii, Idaho, Illinois, Maryland, Massachusetts, Minnesota, Montana, New Jersey, New York, Oregon, Vermont, Washington and West Virginia.

Table 2. Weighted least-squares regression coefficients (and standard errors) indicating effects of state-level variables on birthrates

\begin{tabular}{|c|c|c|c|c|c|}
\hline Variable & Model 1 & Model 2 & Model 3 & Model 4 & Model 5 \\
\hline $\begin{array}{l}\text { Medicaid restriction } \\
\% \text { in poverty } \\
\text { Medicaid restriction }\end{array}$ & $\begin{array}{c}0.02(0.07) \\
-0.06^{\star}(0.03)\end{array}$ & $\begin{array}{l}-0.05(0.04) \\
-0.08^{\star \star}(0.02)\end{array}$ & $\begin{array}{l}-0.05(0.04) \\
-0.06^{\star \star}(0.02)\end{array}$ & $\begin{array}{l}-0.05(0.04) \\
-0.06^{\star \star}(0.02)\end{array}$ & $\begin{array}{l}-0.05(0.04) \\
-0.06^{\star \star}(0.02)\end{array}$ \\
\hline $\begin{array}{l}\mathrm{X} \% \text { in poverty } \\
\text { Abortion providers per }\end{array}$ & $-0.01(0.03)$ & $0.01(0.02)$ & $0.02(0.02)$ & $0.02(0.02)$ & $0.01(0.02)$ \\
\hline $\begin{array}{l}1,000 \text { women } \\
\text { Public spending on }\end{array}$ & na & na & $0.01(0.01)$ & $0.01(0.01)$ & $0.01(0.01)$ \\
\hline $\begin{array}{l}\text { contraception per woman } \\
\text { Family planning clinics }\end{array}$ & na & na & $-0.01(0.01)$ & na & $-0.00(0.01)$ \\
\hline per 1,000 women & na & na & na & $-0.01(0.01)$ & na \\
\hline$\%$ of women in labor force & na & na & $0.22^{\star \star}(0.07)$ & $0.22^{* \star}(0.07)$ & $0.20^{\star \star}(0.07)$ \\
\hline Marriages per 1,000 persons & na & na & $0.20^{\star \star}(0.03)$ & $0.20^{\star \star}(0.03)$ & $0.20^{\star *}(0.03)$ \\
\hline Women as $\%$ of legislators & na & na & na & na & 0.00 \\
\hline $\begin{array}{l}\text { Parental involvement enforced } \\
\text { Parental involvement }\end{array}$ & na & na & na & na & $0.01(0.01)$ \\
\hline not enforced & na & na & na & na & $0.02^{\star *}(0.01)$ \\
\hline $\begin{array}{l}\text { Intercept } \\
F\end{array}$ & $\begin{array}{l}4.45^{\star *}(0.07) \\
33.69\end{array}$ & $\begin{array}{l}4.73^{* *}(0.04) \\
100.29\end{array}$ & $\begin{array}{l}3.30^{* *}(0.30) \\
108.92\end{array}$ & $\begin{array}{l}3.23^{* \star}(0.30) \\
08.82\end{array}$ & $\begin{array}{l}3.36^{* *}(0.31) \\
109.99\end{array}$ \\
\hline
\end{tabular}

${ }^{*} \mathrm{p}<.05$. ${ }^{* *} \mathrm{p}<.01$. Notes: In this table and in Table 3, Models $1-4$ are based on 561 observations, and Model 5 is based on 550 observations (because the variable "women as \% of legislators" does not apply to the District of Columbia). All models include year and state dummy variables, and Models $2-5$ include a time trend interacted with the state dummy variable. na=not applicable.

was enforced ${ }^{28}$ and the portion of the year during which such a restriction, although enacted, was not enforced. ${ }^{29}$ These variables serve simultaneously as controls for time-varying state effects (since the fixedeffects model controls for unobserved, time-invariant state effects, but not for timevarying, state-specific effects) and as an additional test of the role of state sentiments.

The representation of women in state legislatures varies widely, probably because of differences in state cultures and environments. ${ }^{30}$ It tends to be highest in the Northeast and West, and lowest in the South. Further, women's representation has been changing at different rates in each state. For example, between 1979 and 1991, the proportion of state legislative offices held by women increased from $10 \%$ to $29 \%$ in Idaho and decreased from $7 \%$ to $5 \%$ in Kentucky.

Parental involvement restrictions are not expected to have a direct impact on the overall abortion rate or birthrate because these restrictions apply only to women younger than 18 who would not have talked to their parents in the absence of the restriction. The enactment and enforcement of parental involvement restrictions, however, may be associated with state sentiments toward women, nonmarital sex and abortion, and thus may have an indirect impact on aggregate abortion rates and birthrates. Numerous states have enacted parental involvement restrictions but either have not enforced them or have enforced them for limited time periods.

The marriage rate ${ }^{31}$ and labor-force participation rate $\mathrm{e}^{32}$ are included because marital status and employment status may have an impact on decisions concerning family size or pregnancy resolution. For example, in 1987, there were about 46 abortions per 1,000 unmarried women of childbearing age and nine per 1,000 married women. ${ }^{33}$ In 1994 and 1995, married women obtained $18 \%$ of abortions, and unmarried women obtained $82 \%$; currently employed women obtained $66 \%$ of abortions, while women who were not employed obtained 34\%. ${ }^{34}$

The empirical model does not include all independent variables that may affect birthrates and abortion rates. For example, it does not include a measure reflecting the effects of the Medicaid eligibility expansions of the 1980s. These expansions increased the number of low-income women and children who qualified for free obstetric and pediatric care; they also increased the number of women who qualified for Medicaid-funded abortions.

Sixteen states and the District of Columbia used their Medicaid funds to pay for abortions in 1996; ${ }^{\dagger}$ all but one of these (New York) included abortions for women who qualify under the expansions. ${ }^{35} \mathrm{How}-$ ever, many states do not have written policies, and most do not publish information or advertise the new funding for abortions. The most recent Alan Guttmacher Institute (AGI) survey of Medicaid agencies suggested that fewer than 200 Medicaid-funded abortions were provided to women who qualified under the expansions. ${ }^{36} \mathrm{Al}-$ most none of the empirical research on abortion rates and birthrates has included a measure of changes in Medicaid income eligibility in the late 1980s; however, one study using data from three states found a very small effect of the Medicaid expansions on the probability of abortion among 19-27-year-old nonblack women. ${ }^{37}$ 
Also excluded is a measure of the effect of support through Aid to Families with Dependent Children (AFDC). Although the results of empirical studies are mixed, many find no effect of AFDC on rates of abortions and births. ${ }^{38}$

Data on births by state and by year were obtained from the vital statistics of the United States, ${ }^{39}$ and numbers of women were obtained from census data. ${ }^{40}$ Data on abortions by state and by year were provided by AGI. ${ }^{41}$ Abortion and birth data are reported by state of occurrence rather than by state of residence. Thus, they include abortions and births among state residents and nonresidents.

If the enforcement of abortion restrictions influences the extent to which women travel across state lines to obtain abortions or give birth, then using data by state of occurrence may bias the empirical results. Fortunately, the use of these data to estimate the effect of Medicaid funding restrictions is not particularly problematic, because Medicaid-eligible individuals cannot escape their state's funding restriction by traveling to a state without a funding restriction. For example, residents of Pennsylvania, a state with a restrictive funding policy, would not be immediately eligible for Medicaid in New York.

The regression equation is estimated in log-linear form, using pooled time-series cross-sectional state data for 11 years: 1978-1982, 1984-1985, 1987-1988 and 1991-1992. Data for 1983, 1986, 1989 and 1990 are not included because AGI did not conduct surveys in those years, and the numbers of abortions and abortion providers are therefore not available. Since the data are grouped by state, the minimum chi-square, or weighted leastsquares, method is utilized. ${ }^{42}$

\section{Results}

The estimated coefficients for the birth and abortion equations are reported in Tables 2 and 3 , respectively. Each table shows results for five models, including various combinations of the independent variables. All of the models include state dummy variables that control for unobserved time-invariant differences across states and year dummy variables that control for unobserved time-varying factors that are constant across all states. All but the first also include a time trend interacted with the state dummy variables; this controls for time-varying linear differences across states.

Restrictions on Medicaid funding for abortion have little, if any, effect on women's reproductive decisions. The re-

Table 3. Weighted least-squares regression coefficients (and standard errors) indicating effects of state-level variables on abortion rates

\begin{tabular}{|c|c|c|c|c|c|}
\hline Variable & Model 1 & Model 2 & Model 3 & Model 4 & Model 5 \\
\hline $\begin{array}{l}\text { Medicaid restriction } \\
\% \text { in poverty } \\
\text { Medicaid restriction }\end{array}$ & $\begin{array}{r}0.01(0.12) \\
-0.04(0.05)\end{array}$ & $\begin{array}{l}-0.09(0.12) \\
-0.06(0.04)\end{array}$ & $\begin{array}{l}-0.11(0.12) \\
-0.06(0.04)\end{array}$ & $\begin{array}{l}-0.11(0.12) \\
-0.06(0.04)\end{array}$ & $\begin{array}{l}-0.04(0.12) \\
-0.03(0.04)\end{array}$ \\
\hline $\begin{array}{l}x \% \text { in poverty } \\
\text { Abortion providers per }\end{array}$ & $-0.03(0.05)$ & $0.01(0.05)$ & $0.03(0.05)$ & $0.03(0.05)$ & $0.00(0.05)$ \\
\hline $\begin{array}{l}1,000 \text { women } \\
\text { Public spending on }\end{array}$ & na & na & $0.25^{\star \star}(0.04)$ & $0.24^{\star \star}(0.04)$ & $0.25^{\star \star}(0.04)$ \\
\hline $\begin{array}{l}\text { contraception per woman } \\
\text { Family planning clinics per }\end{array}$ & na & na & $0.01(0.02)$ & na & $0.01(0.02)$ \\
\hline 1,000 women & na & na & na & $-0.05(0.03)$ & na \\
\hline$\%$ of women in labor force & na & na & $0.23(0.20)$ & $0.21(0.19)$ & $0.19(0.21)$ \\
\hline Marriages per 1,000 persons & na & na & $0.03(0.09)$ & $0.03(0.09)$ & $0.06(0.09)$ \\
\hline Women as $\%$ of legislators & na & na & na & na & $0.02(0.03)$ \\
\hline $\begin{array}{l}\text { Parental involvement enforced } \\
\text { Parental involvement }\end{array}$ & na & na & na & na & $0.03(0.02)$ \\
\hline not enforced & na & na & na & na & $0.01(0.02)$ \\
\hline Intercept & $2.13^{* *}(0.13)$ & $2.48^{* *}(0.14)$ & $2.17^{*}(0.89)$ & $2.11^{*}(0.88)$ & $2.10^{*}(0.93)$ \\
\hline$F$ & 234.14 & 195.15 & 209.30 & 209.99 & 138.46 \\
\hline
\end{tabular}

${ }^{*} \mathrm{p}<.05 .{ }^{* *} \mathrm{p}<.01$. Note: See notes to Table 2.

sults in Table 2 suggest that the funding restriction is not associated with a change in the birthrate. ${ }^{*}$ Table 3 shows that the Medicaid funding restriction is associated with either no change or a statistically significant reduction in the abortion rate. ${ }^{\dagger}$

The sum of the coefficient estimates on the Medicaid funding restriction variables in Models 1 and 2 imply that the funding restriction reduces the logarithm of the abortion rate by $0.06-0.07$. Since the weighted mean of the logarithm of the abortion rate is 3.25 , this implies that states with a funding restriction have a $2 \%$ lower abortion rate than those with no such restriction. However, in the models that control for the supply of abortion providers and the demographic characteristics of the state population, the Medicaid funding restriction has no statistically significant impact on the abortion rate.

Inclusion of the proxy variables for state sentiments toward women, nonmarital sex and abortion does not alter the sign or the statistical significance of the estimates of the effect of Medicaid funding restrictions on the abortion rate or birthrate.

Neither public spending on contraceptive services nor the availability of family planning clinics is associated with abortion rates or birthrates. One possible explanation for this is that women's reproductive choices may not be sensitive to the prices of contraceptive services. Another possibility is that the women who are most likely to use contraceptives are also the most fecund women, and the coefficient estimates on the variables measuring the availability of family planning programs are therefore biased downward.

Increased availability of abortion providers is associated with higher abortion rates. This result is not surprising, since the abortion data are by state of occurrence and women travel across state lines to obtain abortions. The more interesting result is that the availability of abortion providers is not associated with the birthrate, which suggests that women's decisions to give birth are not sensitive to the time and travel costs of obtaining an abortion.

Finally, the demographic characteristics of the population are associated with the birthrate, but not with the abortion rate. Birthrates are higher in states with higher rates of female labor-force participation, higher marriage rates and lower poverty rates.

\section{Discussion}

The results of this empirical analysis suggest that women's reproductive choices are not significantly influenced by state regulations that limit state subsidies for abortion services or by federal and state subsidies for contraceptive services. Further, the findings do not support the hypothesis that increasing the costs of engaging in sexual activity (for example, by raising the costs of obtaining an abortion)

*The sum of the coefficients on the Medicaid funding restriction variable and its interaction with the percentage of the population below the poverty level is used as an estimate of the regulatory effect. In all five models in Table 2, the hypothesis that Medicaid funding restrictions have no effect on birthrates cannot be rejected. The F statistics for Models 1-5 are 1.3, 2.7, 1.3, 1.2 and 1.5, respectively.

tThe null hypothesis that the coefficients on the Medicaid restriction variable and its interaction with the proportion in poverty are simultaneously equal to zero can be rejected at the $5 \%$ level of significance in the equations that do not control for the supply of abortion providers or the demographic characteristics of the state population. The F statistics for Models 1-5 in Table 3 are 6.9, 5.6, $1.6,1.7$ and 1.7 , respectively. 
will reduce sexual activity and thus decrease pregnancy rates and birthrates.

One might argue that the Medicaid funding restriction had no association with the birthrate because the restriction reduced the pregnancy rate and increased the ratio of births to pregnancies, and that these two changes canceled each other out. However, the results of the analysis on the impact of the Medicaid funding restriction on abortion rates do not support this argument. The Medicaid funding restrictions do not appear to lower the abortion rate, at least in models that control for the availability of abortion providers and other variables. This suggests that the restrictions do not decrease the pregnancy rate or the ratio of abortions to pregnancies (and thus do not increase the ratio of births to pregnancies).

A possible explanation of these results is that reduced-cost abortions may still be available to some low-income women in states that restrict Medicaid funding. For example, in 1978, North Carolina created a special fund to pay for abortions for low-income women. ${ }^{43}$ Prior to Webster v. Reproductive Health Services, large metropolitan public hospitals provided reduced-cost abortions to low-income women. ${ }^{44}$

Further, abortion clinics adopt a variety of policies to reduce the cost of abortions for low-income women. For example, the $\mathrm{Na}$ tional Abortion Federation requires that its members have "policies to accommodate low-income women," and strongly recommends that "specific financial arrangements" be made available to a "minimum of ten percent of the patient load." The Planned Parenthood Federation of America's Justice Fund is intended to help lowincome women obtain abortions. ${ }^{45}$

Empirical evidence suggests that the availability of free or reduced-cost abortions (excluding those covered by Medicaid) is greatest in states where Medicaid funding is restricted. Some $33 \%$ of nonhospital abortion providers offered free or reduced-cost services in states that restricted Medicaid funding, compared with $26 \%$ in states that used Medicaid funds to pay for abortions. ${ }^{46}$

Limitations of the data are another possible explanation for the finding that Medicaid funding restrictions and public subsidies for family planning services have no statistically significant effect. Data on the number of abortions obtained by women of all income levels are utilized because information on the use of abortion by state, year and income are not available. Government policies that decrease subsidies for abortion or increase subsi- dies for other family planning services target poor women, and the use of aggregate abortion rates may hide the effects of these targeted policies.

In fact, results of a recent survey of abortion patients suggested that "in states where Medicaid pays for abortions, women covered by Medicaid have an abortion rate 3.9 times that of women who are not covered by Medicaid, while in states that do not permit Medicaid funding for abortions, Medicaid recipients are 1.6 times as likely as nonrecipients to have abortions." 47

Despite the data limitations, however, the empirical results from several fixedeffect specifications are quite consistent. Inclusion or exclusion of variables measuring provider availability, demographic characteristics and state sentiments toward women and women's reproductive choices does not alter the estimate of the effect of Medicaid funding restrictions on the birthrate. The results consistently suggest that Medicaid funding restrictions do not affect the birthrate.

A related issue is what empirical estimates of the effect of Medicaid funding restrictions on abortion and birthrates can tell us about the relationship between Medicaid funding restrictions and pregnancy rates. For at least two reasons, estimates of the impact of abortion restrictions on birthrates and abortion rates cannot be used to determine the impact of Medicaid funding restrictions on pregnancy rates.

First, the number of pregnancies is the sum of the numbers of births, abortions and miscarriages. Although $10-15 \%$ of pregnant women have miscarriages, ${ }^{48}$ data by state and year are not available.

Second, it cannot be assumed that miscarriages are randomly distributed across states. The risk of miscarriage may increase with maternal alcohol consumption, ${ }^{49}$ cocaine use ${ }^{50}$ and smoking. ${ }^{51}$ Miscarriages may be more frequent in states that restrict Medicaid funding for abortions if more unwanted pregnancies are not aborted and if women with unwanted pregnancies are more likely to pursue unhealthy behavior, such as using alcohol, drugs and tobacco products.

Between 1978 and 1992, a period of increasing abortion restrictiveness, the rate of miscarriages per 1,000 women aged $15-44$ increased from 13.5 to $15.1 .{ }^{52}$ In other words, even if empirical results suggested that Medicaid funding restrictions were associated with lower abortion rates and birthrates, this would not be proof that Medicaid funding restrictions were associated with lower pregnancy rates.
In the 1992 Planned Parenthood v. Casey decision, the U.S. Supreme Court granted states the right to impose restrictions on the provision of abortion services as long as the restrictions do not "unduly burden" a woman's right to choose. Currently, states are enforcing mandatory waiting period laws, bans on the use of public facilities for abortion, prohibitions on the participation of public employees in providing abortion services, procedurespecific abortion bans and prohibitions of abortion coverage in state employees' health insurance, in addition to Medicaid funding restrictions and parental involvement laws. ${ }^{53}$ More research on the impact of state-level restrictions is greatly needed; such research should focus particularly on the years since 1992 and on estimating the impact of multiple state-level abortion restrictions.

\section{References}

1. M. Wilder, National Abortion and Reproductive Rights Action League (NARAL), memorandum, Washington, D. C., Jan. 14, 1997.

2. D. Haas-Wilson, "The Impact of State Abortion Restrictions on Minors' Demand for Abortions," Journal of Human Resources, 31:140-158, 1996; R. Ohsfeldt and S. Gohmann, "Do Parental Involvement Laws Reduce Adolescent Abortion Rates?" Contemporary Economic Policy, 12:65-76, 1994; S. Lundberg and R. D. Plotnick, "Effects of State Welfare, Abortion and Family Planning Policies on Premarital Childbearing Among White Adolëscents," Family Planning Perspectives, 22:246-251 \& 275, 1990; and S. Singh, "Adolescent Pregnancy in the United States: An Interstate Analysis," Family Planning Perspectives, 18:210-220, 1986.

3. D. Haas-Wilson, "The Economic Impact of State Restrictions on Abortion: Parental Consent and Notification Laws and Medicaid Funding Restrictions," Journal of Policy Analysis and Management, 12:498-511, 1993; and R. Blank, C. George and R. London, "State Abortion Rates: The Impact of Policies, Providers, Politics, Demographics, and Economic Environment," Journal of Health Economics, 15:513-553, 1996.

4. T. Joyce and R. Kaestner, "State Reproductive Policies and Adolescent Pregnancy Resolution: The Case of Parental Involvement Laws," Journal of Health Economics, 15:579-607, 1996; P. J. Cook et al., "The Effects of ShortTerm Variation in Abortion Funding on Pregnancy Outcomes," Working Paper, National Bureau of Economic Research, New York, 1996; P. B. Levine, A. B. Trainor and D. J. Zimmerman, "The Effect of Medicaid Abortion Funding Restrictions on Abortions, Pregnancies, and Births," Journal of Health Economics, 15:555-578, 1996; and S. Matthews, D. Ribar and M. Wilhelm, "The Effects of Economic Conditions and Access to Reproductive Health Services on State Abortion Rates and Birthrates," Family Planning Perspectives, 29:52-60, 1997.

5. R. Posner, Sex and Reason, Harvard University Press, Cambridge, Mass., 1992.

6. G. Akerlof, J. Yellen and M. Katz, "An Analysis of Outof-Wedlock Childbearing in the United States," Quarterly Journal of Economics, 111:277-317, 1996.

7. K. J. Meier and D. R. McFarlane, "State Family Planning and Abortion Expenditures: Their Effect on Public Health," American Journal of Public Health, 84:1468-1472, 1994. 
8. C. Jackson and J. Klerman, "Welfare and American Fertility," RAND, Santa Monica, Calif., 1995.

9. P. J. Cook et al., 1996, op. cit. (see reference 4).

10. R. Ohsfeldt and S. Gohmann, 1994, op. cit. (see reference 2).

11. T. Kane and D. Staiger, "Teen Motherhood and Abortion Access," Quarterly Journal of Economics, 111:467-506, 1996.

12. P. B. Levine, A. B. Trainor and D. J. Zimmerman, 1996 op. cit. (see reference 4 ).

13. T. Joyce and R. Kaestner, 1996, op. cit. (see reference 4)

14. Calculated from data in B. Nestor and R. B. Gold "Public Funding of Contraceptive, Sterilization and Abortion Services, 1982," Family Planning Perspectives, 16:128-133, 1984; and in D. Daley and R. B. Gold, "Public Funding for Contraceptive, Sterilization and Abortion Services, Fiscal Year 1992," Family Planning Perspectives, 25:244-251, 1993.

15. Calculated from data provided by S.K. Henshaw, The Alan Guttmacher Institute (AGI), New York, Sept. 10, 1991.

16. S. Lundberg and R. D. Plotnick, 1990, op. cit. (see reference 2).

17. J.D. Shelton, E. A. Brann and K.F. Schultz, "Abortion Utilization: Does Travel Distance Matter?" Family Planning Perspectives, 8:260-262, 1976; D. Haas-Wilson, 1996, op. cit. (see reference 2); and R. Blank, C. George and R. London, 1996, op. cit. (see reference 3)

18. T. Kane and D. Staiger, 1996, op. cit. (see reference 11)

19. M. Grossman and T. Joyce, "Unobservables, Pregnancy Resolutions, and Birth Weight Production Functions in New York City," Journal of Political Economy, 98:983-1007, 1990

20. R. B. Gold, "After the Hyde Amendment: Public Funding for Abortion in FY 1978," Family Planning Perspectives, 12:131-134, 1980;___, "Publicly Funded Abortions in FY 1980 and FY 1981," Family Planning Perspectives, 14:204-207, 1982; B. Nestor and R. B. Gold, 1984, op cit. (see reference 14); R. B. Gold and J. Macias, "Public Funding of Contraceptive, Sterilization and Abortion Services, 1985," Family Planning Perspectives, 18:259-264, 1986 R. B. Gold and S. Guardado, "Public Funding of Family Planning, Sterilization and Abortion Services, 1987," Family Planning Perspectives 20:228-233, 1988; and NARAL Foundation, Who Decides? A State-by-State Review of Abortion Rights, Washington, D.C., various years.

21. U.S. Bureau of the Census, Statistical Abstract of the United States, U.S. Government Printing Office, Washington, D.C., various years

22. B. Nestor and R. B. Gold, 1984, op. cit. (see reference 14); R. B. Gold and J. Macias, 1986, op. cit. (see reference 20); R. B. Gold and D. Daley, "Public Funding of Contraceptive, Sterilization and Abortion Services, Fiscal Year 1990," Family Planning Perspectives, 23:204-211, 1991; and
D. Daley and R. B. Gold, 1993, op. cit. (see reference 14)

23. A. Torres and J. D. Forrest, "Family Planning Clinic Services in the United States, 1981," Family Planning Perspectives, 15:272-278, 1983; and ——, "Family Planning Clinic Services in the United States, 1983," Family Planning Perspectives, 17:30-35, 1985.

24. M. Grossman and T. Joyce, 1990, op. cit. (see reference 19).

25. S. K. Henshaw, AGI, New York, personal communication, Sept. 10, 1991.

26. R. Blank, C. George and R. London, 1996, op. cit. (see reference 3 ).

27. Center for the American Woman and Politics, Eagleton Institute of Politics, Rutgers University, "Fact Sheet on Women in State Legislatures," New Brunswick, N. J. various years; and —-, "Roster of Women State Legislators," New Brunswick, N.J., various years.

28. N. McLaughlin, NARAL Foundation, "Enactment Dates of Parental Consent/Notice Laws Between January 1, 1977 and December 31, 1992," memorandum, Washington, D.C., Nov. 11, 1994.

29. Ibid.

30. J. Clark, "Getting There: Women in Political Office," Annals of the American Academy of Political and Social Science, 515:63-76, 1991.

31. National Center for Health Statistics (NCHS), "Annual Summary of Births, Marriages, Divorces, and Deaths: United States, 1992," Monthly Vital Statistics Report, Vol. 41, No. 13, 1993; and —- Vital Statistics of the United States: Vol. III-Marriage and Divorce, U.S. Government Printing Office (GPO), Washington, D.C., various years.

32. U.S. Bureau of Labor Statistics, "Geographic Profile of Employment and Unemployment," GPO, various years.

33. S. K. Henshaw, L. M. Koonin and J.C. Smith, "Characteristics of U.S. Women Having Abortions," Family Planning Perspectives, 23:75-81, 1991.

34. S. K. Henshaw and K. Kost, "Abortion Patients in 1994-1995: Characteristics and Contraceptive Use," Family Planning Perspectives, 28:140-147 \& 158, 1996.

35. T. Sollom, AGI, Washington, D.C., personal communication, Sept. 25, 1996.

36. Ibid.

37. T. Joyce and R. Kaestner, "The Effect of Expansions in Medicaid Income Eligibility on Abortion," Demography, 33:181-192, 1996.

38. D. Ellwood and M. Bane, "The Impact of AFDC on Family Structure and Living Arrangements," Research in Labor Economics, 7:137-207, 1985; and R. Blank, C. George and R. London, 1996, op. cit. (see reference 3).

39. NCHS, Vital Statistics of the United States: Vol. I-Natality, various years; __ , "Advance Report of Final Na- tality Statistics, 1991," Monthly Vital Statistics Report, Vol. 42, No. 3, 1993; and — "Births, Marriages, Divorces and Deaths for 1992," Monthly Vital Statistics Report, Vol. 41, No. 12, 1993.

40. U.S. Bureau of the Census, "State Population and Household Estimates, with Age, Sex, and Components of Change," Current Population Reports, Series P-25, No. 1024, 1988; and —-, "State Population Estimates by Age and Sex: 1980 to 1992, "Current Population Reports, Series P-25, No. 1106, 1993.

41. S. K. Henshaw, AGI, New York, personal communication, Sept. 10, 1991.

42. G.S. Maddala, Limited-Dependent and Qualitative Variables in Econometrics, Cambridge University Press, Cambridge, UK, 1983.

43. P. J. Cook et al., 1996, op. cit. (see reference 4).

44. J. Gold and W. Cates, Jr., "Restrictions of Federal Funds for Abortion: 18 Years Later," American Journal of Public Health, 69:929-930, 1979.

45. National Abortion Federation and Planned Parenthood Federation of America, legal brief in Turnock v. Ragsdale, 1989.

46. D. Haas-Wilson, 1993, op. cit. (see reference 3)

47. S. K. Henshaw and K. Kost, "Abortion Patients in 1994-1995: Characteristics and Contraceptive Use," Family Planning Perspectives, 28:140-147 \& 158, 1996

48. Merck and Co., Merck Manual, 15th ed., Rahway, N. J., 1987.

49. M. Russell and J. Skinner, "Early Measures of Maternal Alcohol Misuse as Predictions of Adverse Pregnancy Outcomes," Alcoholism Clinical and Experimental Research, 12:824-830, 1988; L. Murray and M. Iain, "Alcohol and Fetal Damage," Alcohol and Alcoholism, 20:185-188, 1985; E. Abel, "Prenatal Effects of Alcohol," Drug and Alcohol Dependence, 14:1-10, 1984; and I. Barrison and J. Wright, "Moderate Drinking During Pregnancy and Fetal Outcome," Alcohol and Alcoholism, 19:167-172, 1984.

50. J. Rosecan and B. Gross, "Newborn Victims of Cocaine Abuse," Medical Aspects of Human Sexuality, 20:30-35, 1986

51. J. Kline et al., "Cigarette Smoking and Spontaneous Abortion of Known Karyotype," American Journal of Epidemiology, 141:417-427, 1995; and R. A. Walsh, "Effects of Maternal Smoking on Adverse Pregnancy Outcomes: Examination of the Criteria of Causation," Human Biology, 66:1059-1092, 1994.

52. S. J. Ventura et al., "Trends in Pregnancies and Pregnancy Rates: Estimates for the United States, 1980-92," Monthly Vital Statistics Report, Vol. 43, No. 11, Supplement, 1995, Table 1.

53. NARAL Foundation, Who Decides? A State-by-State Review of Abortion and Reproductive Rights, sixth ed., Washington, D.C., 1997 